\title{
Protective effects of cassia seed ethanol extract against carbon tetrachloride-induced liver injury in mice
}

\author{
Qing Xie, Fang-Fang Guo and Wen Zhou \\ Department of Pharmacy, Qilu Hospital of Shandong University, Jinan City, Shandong Province, China
}

Oxidative stress has been recognized as a critical pathogenetic mechanism for the initiation and the progression of hepatic injury in a variety of liver disorders. Antioxidants, including many natural compounds or extracts, have been used to cope with liver disorders. The present study was designed to investigate the hepatoprotective effects of cassia seed ethanol extract (CSE) in carbon tetrachloride $\left(\mathrm{CCl}_{4}\right)$-induced liver injury in mice. The animals were pre-treated with different doses of CSE $(0.5$, $1.0,2.0 \mathrm{~g} / \mathrm{kg}$ body weight) or distilled water for 5 days, then were injected intraperitoneally with $\mathrm{CCl}_{4}(0.1 \%$ in corn oil, v/v, $20 \mathrm{ml} / \mathrm{kg}$ body weight), and sacrificed at 16 hours after $\mathrm{CCl}_{4}$ exposure. The serum aminotransferase activities, histopathological changes, hepatic and mitochondrial antioxidant indexes, and cytochrome P450 2E1 (CYP2E1) activities were examined. Consistent with previous studies, acute $\mathrm{CCl}_{4}$ administration caused great lesion to the liver, shown by the elevation of the serum aminotransferase activities, mitochondria membrane permeability transition (MPT), and the ballooning degeneration of hepatocytes. However, these adverse effects were all significantly inhibited by CSE pretreatment. $\mathrm{CCl}_{4}$-induced decrease of the CYP2E1 activity was dose-dependently inhibited by CSE pretreatment. Furthermore, CSE dramatically decreased the hepatic and mitochondrial malondialdehyde (MDA) levels, increased the hepatic and mitochondrial glutathione (GSH) levels, and restored the activities of superoxide dismutase (SOD), glutathione reductase (GR), and glutathione Stransferase (GST). These results suggested that CSE could protect mice against $\mathrm{CCl}_{4}$-induced liver injury via enhancement of the antioxidant capacity.

Key words: hepatoprotective effects, antioxidant, cassia seed extract, carbon tetrachloride, CYP2E1

Received: 04 November, 2011; revised: 04 April, 2012; accepted: 09 June, 2012; available on-line: 11 June, 2012

\section{INTRODUCTION}

Oxidative stress refers to a cell's state characterized by excessive production of reactive oxygen species (ROS) and/or reduction in antioxidant defense system (Franco et al., 2008). To resist the ROS, organisms possess a host of antioxidant defense systems, including non-enzymatic antioxidants, mainly glutathione (GSH), and antioxidant enzymes such as superoxide dismutase (SOD), glutathione peroxidase (GPx), and catalase (CAT). However, oxidative stress still could occur due to an excess production of ROS and/or a defect of antioxidant molecules, which could cause damage to macromolecules such as DNA, proteins, and lipids. Accumulating evidence has demonstrated that oxidative stress plays a critical role in the initiation and progression of a variety of liver disorders (Medina \& Moreno-Otero, 2005), and many natural antioxidants have been tried to prevent oxidative stressmediated liver injury (Hewawasam et al., 2003; Nwozo \& Oyinloye, 2011; Skinner \& Rangasami, 2002; Srivastava \& Shivanandappa, 2006). The main advantage of nature compounds or extracts is their mild action in comparison to chemically synthesized drugs.

The seeds of Cassia obtusifolia (Leguminosae) are used as a traditional medicine in Japan, Korea and China for the treatment of eye inflammation, photophobia and lacrimation, dysentery, headache, as well as dizziness (Drever et al., 2008; Guo et al., 1998). The chemical constituents of the seeds have been investigated, and a number of anthraquinones isolated. Biological activities of the Cassia obtusifolia extract (COE) including antibacterial activity, inhibitory effects on histamine release, antiplatelet aggregation, memory protection and neuroprotection have been reported (Drever et al., 2008; Kim et al., 2007; Kitanaka et al., 1998; Sung et al., 2004; Yun-Choi et al., 1990). Hepatoprotective effects of Cassia obtusifolia have also been investigated in several studies in which Cassia leaves extracts showed hepatoprotective activity against paracetamol, ethyl alcohol and diethylnitrosamine (Bhakta et al., 2001; Jafri et al., 1999; Pradeep et al., 2007). However, whether the seeds of the plant possess hepatoprotective effects remains unclear.

Carbon tetrachloride $\left(\mathrm{CCl}_{4}\right)$ is a well-known model compound for producing chemical-induced hepatic injury, which has been widely used for the investigation of hepatoprotective agents (Hewawasam et al., 2003; Hsu et al., 2008; Lee et al., 2008). $\mathrm{CCl}_{4}$ toxicity is initiated by the bioactivation of the $\mathrm{CCl}_{4}$ molecule to trichloromethyl free radicals catalyzed by cytochrome P450 isoenzymes (especially cytochrome P4502E1, CYP2E1) (Comporti, 1989; Manibusan et al., 2007). The overproduced free radicals could overwhelm the antioxidant defense system of organisms, resulting in toxicity. CYPE21 plays a pivotal role in $\mathrm{CCl}_{4}$-induced liver injury, and CYP2E1 (-/-) mice did not exhibit apparent liver injury after treatment with $\mathrm{CCl}_{4}$ (Avasarala et al., 2006).

The current study was designed to investigate the hepatoprotective effects of Cassia seed extract (CSE) in mice exposed to $\mathrm{CCl}_{4}$. The serum aminotransferase activities, histopathological changes, activities of CYP2E1, and changes of the hepatic and mitochondrial antioxi-

e-mail: wenzhou25@126.com

Abbreviations: ALT, alanine aminotransferase; AST, aspartate aminotransferase; CSE, cassia seed ethanol extract; CYP2E1, cytochrome P4502E1; GPx, glutathione peroxidase; GR, glutathione reductase; GSH, glutathione; GST, glutathione S-transferase; MDA, malondialdehyde; MPT, mitochondrial membrane permeability transition; ROS, reactive oxygen species;. SOD, superoxide dismutase 
dant systems were measured for evaluation of the protective effects and exploration of the potential mechanisms.

\section{MATERIALS AND METHODS}

Materials. Commercial assay kits for alanine aminotransferase (ALT), aspartate aminotransferase (AST), malondialdehyde (MDA), GSH, SOD, GPx, and glutathione reductase (GR) were bought from Nanjing Jiancheng Bioengineering Institute (Nanjing, China). Aniline and NADPH were purchased from Sigma (St. Louis, $\mathrm{MO}$, USA). BCA protein assay kit was provided by Beyotime Institute of Biotechnology (Shanghai, China). All other chemicals were of the highest quality commercially available.

Preparation of Cassia seed ethanol extract. Cassia seeds, bought from the local pharmacy, were mixed with 8 volumes of ethanol $(80 \%, \mathrm{v} / \mathrm{v})$ for 1 hour, and subjected to continuous hot extraction $\left(60^{\circ} \mathrm{C}, 2\right.$ hours). The resulting extract was filtered and the residue was mixed with another 8 volumes of ethanol $(80 \%, \mathrm{v} / \mathrm{v})$ for further extraction $\left(60^{\circ} \mathrm{C}, 2\right.$ hours). The combined ethanol extract was evaporated to dryness under reduced pressure to yield ethanol extract $(11.0 \%$ of the mass of seeds) and stored at $4^{\circ} \mathrm{C}$ for use.

Animal treatments. Male Kun-Ming mice, weighing 18-22 g, were provided by the Laboratory Animal Center of Shandong University (Jinan, China). The mice had free access to commercial food and tap water, and were maintained in a temperature-controlled environment with a 12-h dark/light cycle. After 7 days of acclimation, the mice were randomized into 5 groups $(\mathrm{n}=10)$. The mice were treated with CSE $(0.5,1.0$, or $2.0 \mathrm{~g} / \mathrm{kg}$ body weight) or distilled water (control group and $\mathrm{CCl}_{4}$ group) by gavage for consecutive 5 days. Three hours after the last dosing, the mice in the $\mathrm{CCl}_{4}$ and $\mathrm{CSE}$ groups were intraperitoneally injected with $\mathrm{CCl}_{4}(0.1 \%, \mathrm{v} / \mathrm{v}$, dissolved in corn oil, $20 \mathrm{ml} / \mathrm{kg}$ body weight) to induce acute liver injury, while the mice in the control group were administered with equal volume of corn oil. The animals were sacrificed at 16 hours after $\mathrm{CCl}_{4}$ intoxication. Blood samples were collected for the measurement of serum aminotransferase activities, while the liver was quickly dissected. Portion of the liver was fixed in 10\% formalin in $10 \mathrm{mM}$ phosphate-buffered saline (PBS) for histological examination, while the remaining parts were snapped in liquid nitrogen and then stored at $-80^{\circ} \mathrm{C}$ until analysis. All procedures were conducted in accordance with the National Institutes of Health Guidelines for the Care and Use of Animals.

Measurement of the ALT and AST activities. The blood samples were centrifuged $(2500 \mathrm{rpm} \times 15 \mathrm{~min}$, $\left.4^{\circ} \mathrm{C}\right)$ for serum collection. The activities of serum ALT and AST were determined using an autoanalyzer (Shimadzu CL-7200, Japan).

Histopathological examination. Fresh liver was fixed in 10\% formalin in $10 \mathrm{mM}$ phosphate-buffered saline (PBS) ( $\mathrm{pH} 7.4$ ) for $18 \mathrm{~h}$, and then were embedded in paraplast. Tissue sections (about $5 \mu \mathrm{m}$ ) were prepared, deparaffinized, dehydrated, stained with haematoxylin and eosin (H\&E), and examined under light microscopy (Olympus, Japan).

Determination of hepatic and mitochondrial lipid peroxidation (LPO) and GSH levels. Liver tissue was homogenized in 9 volumes of cold buffer $(0.01 \mathrm{M}$ Tris/ $\mathrm{HCl}, 0.0001 \mathrm{M}$ EDTA-Na, $0.01 \mathrm{M}$ saccharose, and $0.8 \%$ saline, $\mathrm{pH} 7.4)$ at $4^{\circ} \mathrm{C}$. The homogenate was cen- trifuged at $4^{\circ} \mathrm{C}(2500 \mathrm{rpm} \times 15 \mathrm{~min})$ and the supernatant was used for the determination of the antioxidant system. MDA was used as a marker for the LPO assay. MDA and GSH levels were measured colorimetrically according to the instructions of commercial assay kits.

Mitochondria isolation and function assay. Mitochondria isolation and mitochondrial permeability transition (MPT) assay were performed as described previously (Song et al., 2003). Briefly, freshly prepared mitochondria $(0.5 \mathrm{mg}$ protein $/ \mathrm{ml})$ were equilibrated in $1 \mathrm{ml}$ incubation buffer (containing $250 \mathrm{mM}$ sucrose, $10 \mathrm{mM}$

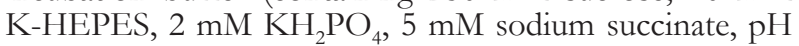
7.2) at $25^{\circ} \mathrm{C}$ for $10 \mathrm{~min}$. Mitochondrial swelling was initiated by the addition of $0.3 \mathrm{mM}$ calcium chloride. The decrease of the absorbance at $540 \mathrm{~nm}$ was determined in consecutive $5 \mathrm{~min}$.

Determination of the activities of antioxidant enzymes. The activities of SOD, GR, GPx, and GST were measured using commercial assay kits (Nanjing Jiancheng Institute, China) according to the manufacturer's instructions. SOD activity was measured following the reduction of nitrite by a xanthine-xanthine oxidase system which is a superoxide anion generator. GR activity was quantified by the depletion of NADPH measured at 340 nm. GPx and GST activities were assayed by the decrease of the GSH levels, which can be determined at $412 \mathrm{~nm}$. The activities were expressed as $\mathrm{U} / \mathrm{mg}$ protein, $\mathrm{U} / \mathrm{g}$ protein, $\mathrm{U} / \mathrm{mg}$ protein and $\mathrm{U} / \mathrm{mg}$ protein, respectively.

Measurement of the CYP2E1 activity. Liver samples were homogenized in 4 volumes (w/v) of cold buffer containing $10 \mathrm{mM}$ Tris- $\mathrm{HCl}, 0.15 \mathrm{M} \mathrm{KCl}, 0.1$ $\mathrm{mM}$ EDTA, $1.0 \mathrm{mM}$ dithiothreitol and $0.01 \mathrm{mM}$ phenylmethoxysulfonyl fluoride. Hepatic microsomal fractions were obtained by ultracentrifugation. Aniline hydroxylase $(\mathrm{ANH})$ was determined as a specific biomarker for CYP2E1 activity with aniline as the substrate according to the procedure described previously (Pahan et al., 1997; Roberts et al., 1995; Yue et al., 2009; Zeng et al., 2009).

Statistical analysis. All data was expressed as mean \pm S.D. SPSS 13.0 statistical software was used for statistical analysis. The data were analyzed using one-way analysis of variance (ANOVA) followed by the StudentNewman-Keuls post hoc test. Differences were considered to be statistically significant at $P<0.05$ level.

\section{RESULTS}

\section{CSE attenuates acute $\mathrm{CCl}_{4}$-induced liver damage}

The ALT and AST activities in mice in the $\mathrm{CCl}_{4}$ group were significantly higher than those of the control mice $(P<0.01)$. However, pretreatment with CSE markedly blunted these alterations in a dose-dependent manner (Fig. 1). Histological examination corresponded well with the biochemical analysis. The liver sections of $\mathrm{CCl}_{4}$-intoxicated mice showed moderate ballooning degeneration and inflammatory cell infiltration, which were much milder in liver sections of the CSE-pretreated mice (Fig.2).

\section{Effect of CSE on $\mathrm{Ca}^{2+-i n d u c e d ~ m i t o c h o n d r i a l ~}$ permeability transition}

MPT, characterized by the progressive permeabilization of the inner mitochondrial membrane, is a reliable marker for mitochondrial function. In order to investigate whether $\mathrm{CSE}$ could attenuate acute $\mathrm{CCl}_{4}$-induced 

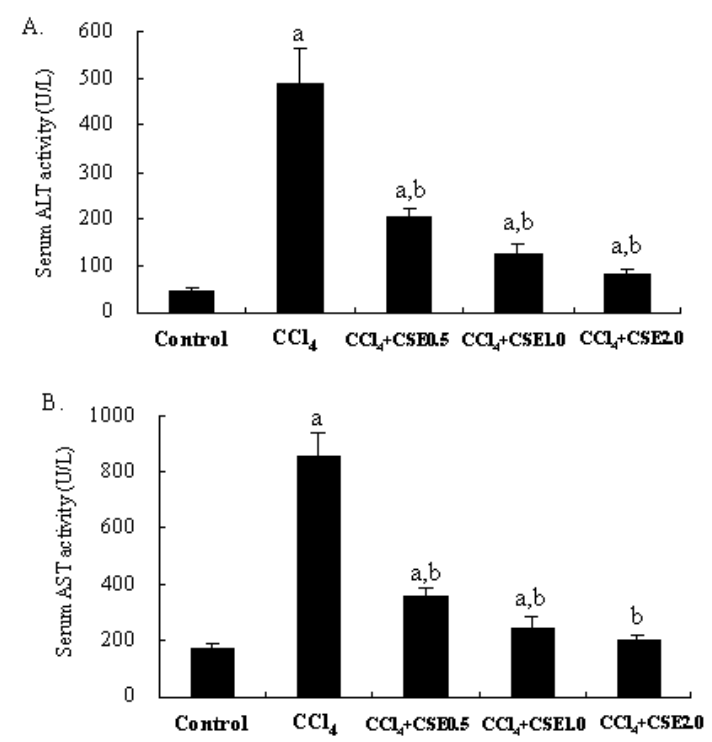

Figure 1. $\mathrm{CSE}$ inhibited $\mathrm{CCl}_{4}$-induced increase of aminotransferase release.

Activities of serum ALT and AST were detected by an automatic analyzer using commercial assay kits, and the data were expressed as $U / L(n=10)$. a $P<0.05$, compared with the control group; ${ }^{b} P<0.05$, compared with the $\mathrm{CCl}_{4}$ group.
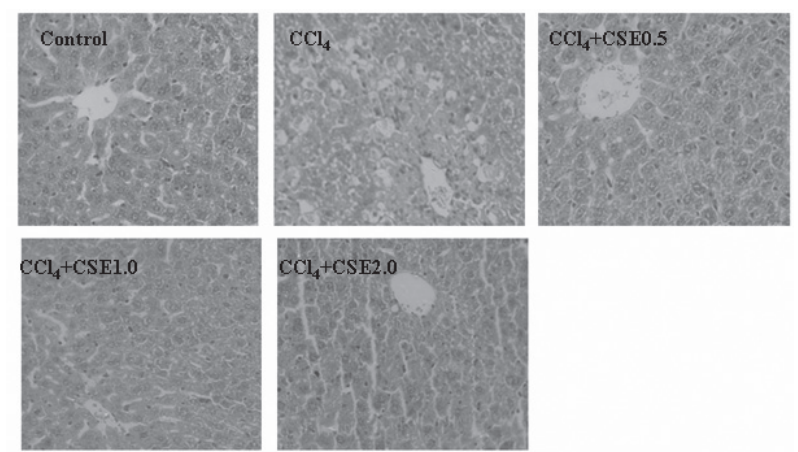

Figure 2. Effects of CSE on hepatic morphological changes in $\mathrm{CCl}_{4}$-exposed mice.

Tissues sections (about $5 \mu \mathrm{m}$ ) were prepared, deparaffinized, dehydrated, stained with haematoxylin and eosin (H\&E) by standard techniques. Magnification, 400x.

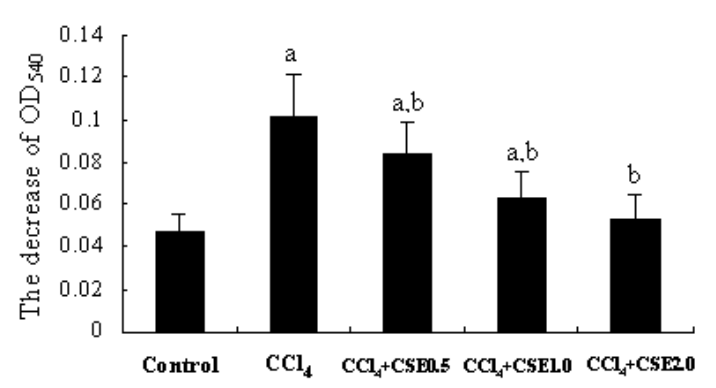

Figure 3. Effects of $\mathrm{CSE}$ and $\mathrm{CCl}_{4}$ on $\mathrm{Ca}^{2+-i n d u c e d ~ m i t o c h o n d r i a l ~}$ permeability transition.

Mitochondria were isolated by differential centrifugation, and diluted to $0.5 \mathrm{mg} / \mathrm{ml}$ in incubation buffer $(250 \mathrm{mM}$ sucrose, $10 \mathrm{mM}$

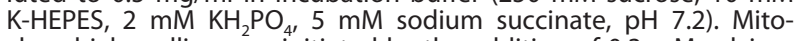
chondrial swelling was initiated by the addition of $0.3 \mathrm{mM}$ calcium chloride. The decrease of absorbance at $540 \mathrm{~nm}$ was determined in consecutive 5 min. a $P<0.05$, compared with the control group; $\mathrm{b} P<0.05$, compared with the $\mathrm{CCl}_{4}$ group. mitochondrial damage, we examined the effects of CSE and $\mathrm{CCl}_{4}$ on $\mathrm{Ca}^{2+}$-induced hepatic mitochondrial permeability transition. The data clearly showed that the absorbance at $540 \mathrm{~nm}\left(\mathrm{OD}_{540}\right)$ was obviously decreased after the addition of $\mathrm{Ca}^{2+}$. The mitochondria isolated from the $\mathrm{CCl}_{4}$-group mice were more sensitive to $\mathrm{Ca}^{2+}$ as shown by a quick decline of $\mathrm{OD}_{540}$. However, CSE attenuated $\mathrm{Ca}^{2+}$-induced MPT, as shown by slow decline of $\mathrm{OD}_{540}$ which mimicked that of control group mice (Fig. 3).

\section{Effects of CSE on hepatic and mitochondrial MDA and} GSH levels

Acute $\mathrm{CCl}_{4}$ exposure resulted in the enhancement of LPO in the liver homogenate as well as in isolated mitochondria. Compared with those of the control group, the MDA levels of liver homogenate and mitochondria were increased by $88.03 \% \quad(P<0.01)$ and $131.76 \%$ $(P<0.01)$, respectively, which was dramatically inhibited by CSE treatment (Fig. 4A). The hepatic and mitochondrial GSH levels of the $\mathrm{CCl}_{4}$-group mice were all markedly decreased compared to those of the control mice $(P<0.01)$. These adverse effects were significantly attenuated in CSE-pretreated mice. Compared with those of $\mathrm{CCl}_{4}$-group mice, the hepatic GSH levels in CSEpretreated mice were increased by $47.77 \%, 55.11 \%$, and $63.95 \%(P<0.01)$, respectively, while the mitochondrial GSH levels were increased by $92.43 \%, 107.19 \%$, and $141.38 \%(P<0.01)$, respectively (Fig. 4B).

Effects of CSE on the activities of hepatic antioxidant enzymes

Compared with the control group, $\mathrm{CCl}_{4}$ reduced the activities of SOD, GR and GST by $34.66 \%, 13.25 \%$ and $26.06 \%(P<0.01)$, respectively, while the GPx activity showed no significant changes $(P>0.05)$. CSE dramatically boosted the activities of SOD, GR and GST $(P<0.05)$, but it did not affect the GPx activity (Table 1).

\section{Effect of CSE on CYP2E1 activity}

In view of the critical role of CYP2E1 in the bioactivation of $\mathrm{CCl}_{4}$, the effects of CSE on the enzyme were examined. $\mathrm{CCl}_{4}$ caused a dramatic decrease of $\mathrm{CY}$ P2E1 activity, which was restored by CSE pretreatment (Fig. 5).

\section{DISCUSSION}

In the current study, the hepatoprotective effects of CSE were investigated in $\mathrm{CCl}_{4}$-exposed mice, which is a widely used animal model. The well-known biomarkers of liver injury (ALT and AST), the mitochondrial function indexes ( $\mathrm{Ca}^{2+}$-induced MPT), and histological changes, were examined for the evaluation of the protective effects of CSE. Consistent with previous studies, our study confirmed that acute $\mathrm{CCl}_{4}$ exposure damaged the liver, as shown by the elevation of the serum aminotransferase activities, the dysfunction of mitochondria, and morphological changes. Interestingly, these adverse effects were significantly attenuated by CSE pretreatment, which indicated a prominent hepatoprotective effect of $\mathrm{CSE}$ against $\mathrm{CCl}_{4}$.

It has been well documented that $\mathrm{CCl}_{4}$ toxicity results from the bioactivation of the $\mathrm{CCl}_{4}$ molecule to trichloromethyl free radicals by cytochrome P450 isoenzymes (Comporti, 1989; Manibusan et al., 2007; Sheweita et al., $2001 \mathrm{~b})$. The free radicals are highly reactive and are capable of covalently binding locally to cellular macromolecules with preference for fatty acids from membrane 

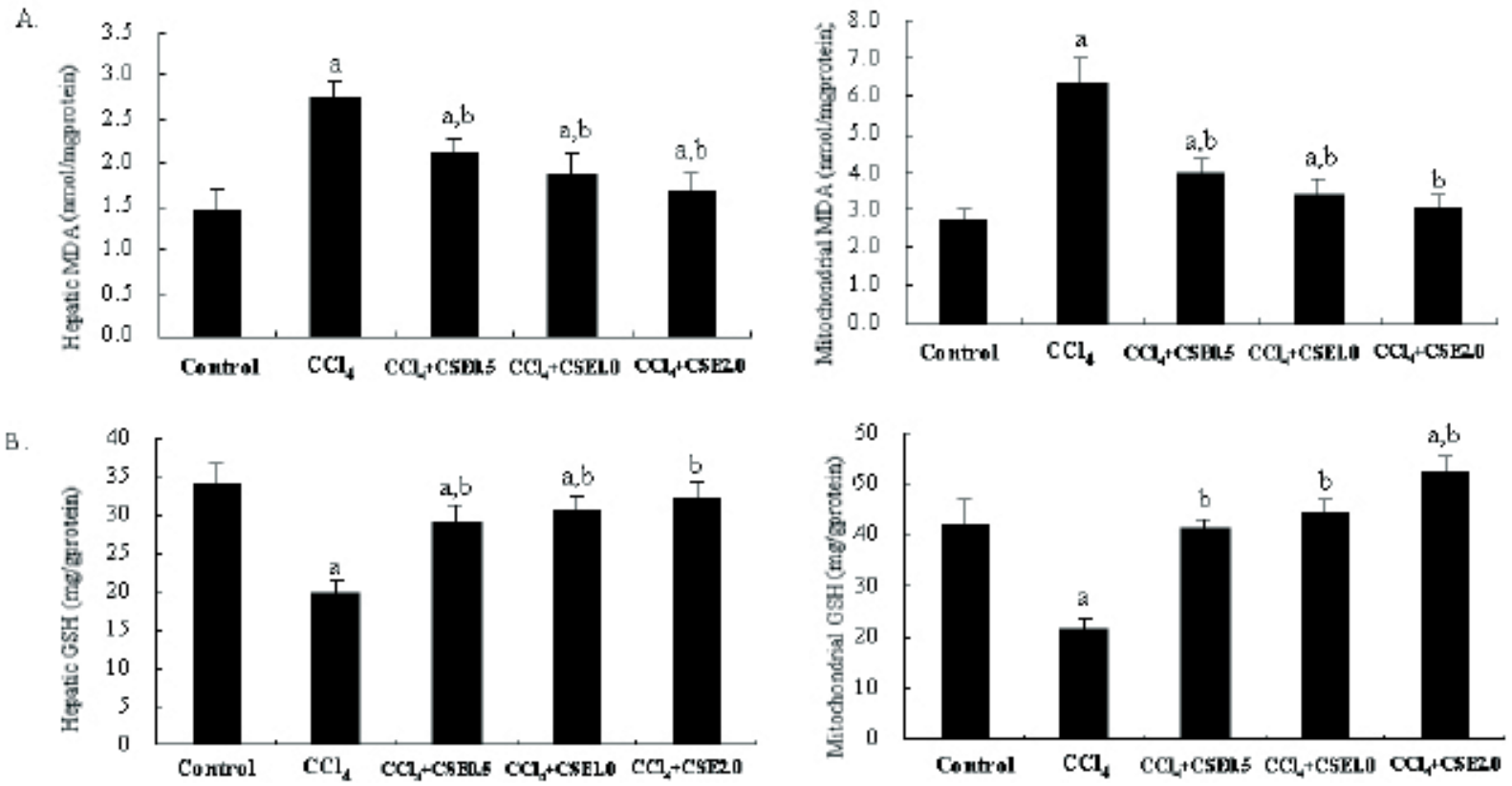

Figure 4. Effects of CSE and $\mathrm{CCl}_{4}$ on hepatic and mitochondrial MDA and GSH levels.

Data are shown as mean \pm S.D. $(n=10)$. a $P<0.05$, compared with the control group; ${ }^{b} P<0.05$, compared with the $C C I_{4}$ group.

phospholipids. Free radicals and the following lipid peroxidation can attack polyunsaturated fatty acids in the biomembrane, damage membrane enzymes, and disrupt cell energy generation and protein synthesis. Mitochondria contain large amounts of polyunsaturated fatty acids in phospholipids and thus are usually more susceptible to oxidative stress. In the present study, MDA level was used as a biomarker of lipid peroxidation, and we found that the hepatic and mitochondrial MDA levels were significantly increased in $\mathrm{CCl}_{4}$ group by $88.03 \%$ and $137.16 \%$, respectively, when compared to those of the control mice. Similarly to the changes of serum aminotransferase activities, the hepatic MDA levels of CSEpretreated mice were significantly lower than in the $\mathrm{CCl}_{4}$ group, which indicated that CSE pretreatment inhibited acute $\mathrm{CCl}_{4}$-induced LPO (Fig. 4).

In order to resist the oxidative stress, organisms possess a host of antioxidant systems, including the nonenzymatic system (mainly GSH) and a series of antioxidant enzymes (e.g., SOD, GR, GPx and GST). Among them, the GSH-related antioxidant system plays crucial role in the antioxidant defense, nutrient metabolism, and regulation of cellular events (Wu et al., 2004). GSH is the predominant low-molecular-weight thiol in animal cells, and can effectively scavenge free radicals and other ROS (e.g., hydroxyl radical, lipid peroxy radical, peroxynitrite, and $\mathrm{H}_{2} \mathrm{O}_{2}$ ) through non-enzymatic and enzymatic process in which the GSH is oxidized to glutathione disulfide (GSSG). The GSSG can be reduced to GSH by glutathione reductase (GR) with the consumption of NADPH (Fang et al., 2002). GPx catalyzes the GSH-dependent reduction of $\mathrm{H}_{2} \mathrm{O}_{2}$ and other peroxides. Moreover, GSH can also react with various electrophiles, physiological metabolites and xenobiotics to form mercapturates, a reaction catalyzed by GST (Lei, 2002). In addition to the GSH-related antioxidant system, SOD has also been demonstrated to play an important role in antioxidant defense system. Similarly to previous reports, acute $\mathrm{CCl}_{4}$ exposure significantly decreased the activities of SOD, GR, GST and the levels of GSH, while the GPx activity was not affected (Di Simplicio \& Mannervik, 1983; Dwivedi et al., 2006; Hsu et al., 2008; Sheweita et al., 2001a). However, CSE pretreatment effectively blocked the $\mathrm{CCl}_{4}$-induced impairment of the antioxidant system (Table 1). $\mathrm{CCl}_{4}$ dramatically decreased the hepatic GSH level (42.38\%), and the mitochondrial GSH pool was impaired even more as expected (49.10\%). Compared with those in mice of the $\mathrm{CCl}_{4}$ group, the hepatic and mitochondrial GSH levels were simultaneously increased in mice of the CSE-pretreated groups in a dosedependent manner. The activation of the SOD and GST could accelerate the clearance of free radicals, while the

Table 1. Effects of CSE on activities of hepatic antioxidant enzymes

\begin{tabular}{|c|c|c|c|c|}
\hline Group & $\begin{array}{l}\text { SOD } \\
\text { (U/mg protein) }\end{array}$ & $\begin{array}{l}\text { GR } \\
\text { (U/g ptotein ) }\end{array}$ & $\begin{array}{l}\text { GPx } \\
\text { (U/mg protein) }\end{array}$ & $\begin{array}{l}\text { GST } \\
\text { (U/mg protein) }\end{array}$ \\
\hline Control & $387.56 \pm 27.65$ & $7.73 \pm 0.31$ & $144.12 \pm 17.59$ & $28.21 \pm 2.93$ \\
\hline $\mathrm{CCl}_{4}$ & $253.24 \pm 51.62^{\mathrm{a}}$ & $6.71 \pm 0.40^{a}$ & $131.74 \pm 16.52$ & $20.86 \pm 1.32^{\mathrm{a}}$ \\
\hline $\mathrm{CCl}_{4}+\mathrm{CSE} 0.5$ & $343.90 \pm 23.97^{b}$ & $7.23 \pm 0.21^{b}$ & $135.06 \pm 13.51$ & $29.37 \pm 2.80^{b}$ \\
\hline $\mathrm{CCl}_{4}+\mathrm{CSE} 1.0$ & $363.94 \pm 26.06^{b}$ & $7.78 \pm 0.29^{b}$ & $134.71 \pm 14.56$ & $31.16 \pm 2.54^{b}$ \\
\hline $\mathrm{CCl}_{4}+\mathrm{CSE} 2.0$ & $392.69 \pm 39.33^{b}$ & $8.13 \pm 0.31^{b}$ & $139.85 \pm 13.80$ & $32.51 \pm 2.15^{b}$ \\
\hline
\end{tabular}

Data are shown as mean \pm S.D. $(n=10)$. ${ }^{\mathrm{a}}<<0.05$, compared with the control group; ${ }^{\mathrm{b}} \mathrm{P}<0.05$, compared with the $C C \mathrm{Cl}_{4} \mathrm{group}$ 


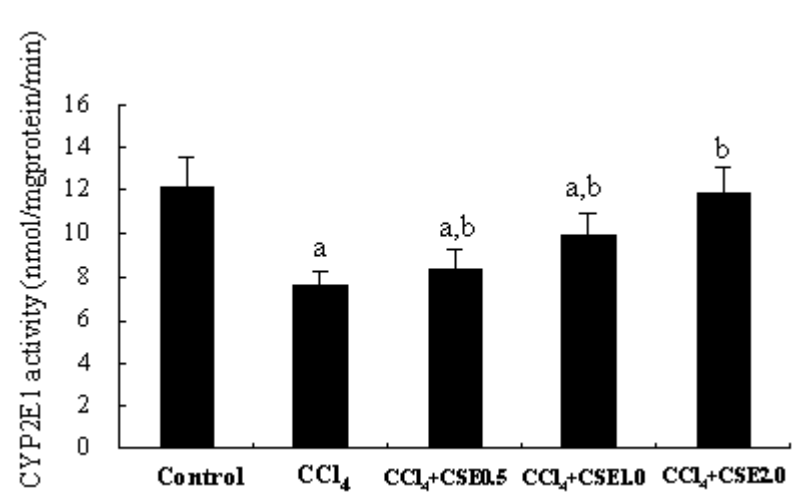

Figure 5. Effects of CSE and $\mathrm{CCl}_{4}$ on CYP2E1 activity.

Liver microsome was prepared by ultracentrifugation. The activity of CYP2E1 was measured with aniline as substrate. Data are shown as mean \pm S.D. a $P<0.05$, compared with the control group; $\mathrm{b} P<0.05$, compared with the $\mathrm{CCl}_{4}$ group.

activation of GR could hasten the biotransformation of GSSG to GSH. All these data suggest that the protective effects of CSE could be associated with the antioxidant activity.

$\mathrm{CCl}_{4}$-induced toxicity requires $\mathrm{CCl}_{4}$ metabolism by CYP2E1. In previous studies, CYP2E1 inhibitors protected against $\mathrm{CCl}_{4}$-induced hepatotoxicity (Fukao et al., 2004; Yang et al., 2001). Furthermore, several studies showed that $\mathrm{CCl}_{4}$ did not induce apparent liver damage in CYP2E1-null mice, which provides direct evidence for the important role of CYP2E1 in $\mathrm{CCl}_{4}$-induced toxicity (Avasarala et al., 2006; Wong et al., 1998). In the current study, we found that CYP2E1 activity was significantly decreased by $\mathrm{CCl}_{4}$ treatment, and was restored by CSE pretreatment (Fig. 5). Similar results have also been obtained in other studies (Tierney et al., 1992; Weerachayaphorn et al., 2010). In fact, previous studies have demonstrated that the reactive radicals produced from $\mathrm{CCl}_{4}$ could bind covalently to CYP2E1, causing suicidal inactivation of the enzyme (Fernandez et al., 1982). The less pronounced reduction of the CYP2E1 activity in CSE-treated mice could also reflect the protection of CSE against $\mathrm{CCl}_{4}$ toxicity.

In summary, the current study demonstrated that CSE showed a potent protective effect against $\mathrm{CCl}_{4}$-induced liver injury. CSE pretreatment significantly inhibited the increase of the serum aminotransferase activities, attenuated oxidative stress-induced mitochondrial dysfunction, and decreased the pathological changes. CSE boosted the activities of antioxidant enzymes and elevated hepatic GSH levels, which could account for its hepatoprotective activity.

\section{REFERENCES}

Avasarala S, Yang L, Sun Y, Leung AW, Chan WY, Cheung WT, Lee SS (2006) A temporal study on the histopathological, biochemical and molecular responses of $\mathrm{CCl}(4)$-induced hepatotoxicity in $\mathrm{Cy}$ p2e1-null mice. Toxicology 228: 310-322.

Bhakta T, Banerjee S, Mandal SC, Maity TK, Saha BP, Pal M (2001) Hepatoprotective activity of Cassia fistula leaf extract. Phytomedicine 8: 220-224.

Comporti M (1989) Three models of free radical-induced cell injury. Chem Biol Interact 72: 1-56.

Di Simplicio P, Mannervik B (1983) Enzymes involved in glutathione metabolism in rat liver and blood after carbon tetrachloride intoxication. Toxicol Lett 18: 285-289.

Drever BD, Anderson WG, Riedel G, Kim DH, Ryu JH, Choi DY, Platt B (2008) The seed extract of Cassia obtusifolia offers neuroprotection to mouse hippocampal cultures. J Pharmacol Sci 107: 380-392.
Dwivedi S, Sharma R, Sharma A, Zimniak P, Ceci JD, Awasthi YC, Boor PJ (2006) The course of CCl4 induced hepatotoxicity is altered in mGSTA4-4 null (-/-) mice. Toxicology 218: 58-66.

Fang YZ, Yang S, Wu G (2002) Free radicals, antioxidants, and nutrition. Nutrition 18: 872-879.

Fernandez G, Villarruel MC, de Toranzo EG, Castro JA (1982) Covalent binding of carbon tetrachloride metabolites to the heme moiety of cytochrome P-450 and its degradation products. Res Commun Chem Pathol Pharmacol 35: 283-290.

Franco R, Schoneveld O, Georgakilas AG, Panayiotidis MI (2008) Oxidative stress, DNA methylation and carcinogenesis. Cancer Lett 266: 6-11.

Fukao T, Hosono T, Misawa S, Seki T, Ariga T (2004) Chemoprotective effect of diallyl trisulfide from garlic against carbon tetrachloride-induced acute liver injury of rats. Biofactors 21: 171-174.

Guo H, Chang Z, Yang R, Guo D, Zheng J (1998) Anthraquinones from hairy root cultures of Cassia obtusifflia. Phytochemistry 49: 16231625.

Hewawasam RP, Jayatilaka KA, Pathirana C, Mudduwa LK (2003) Protective effect of Asteracantha longifolia extract in mouse liver injury induced by carbon tetrachloride and paracetamol. J Pharm Pharmacol 55: 1413-1418.

Hsu YW, Tsai CF, Chang WH, Ho YC, Chen WK, Lu FJ (2008) Protective effects of Dunaliella salina - a carotenoids-rich alga, against carbon tetrachloride-induced hepatotoxicity in mice. Food Chem Toxicol 46: 3311-3317.

Jafri MA, Jalis Subhani M, Javed K, Singh S (1999) Hepatoprotective activity of leaves of Cassia occidentalis against paracetamol and ethyl alcohol intoxication in rats. I Ethnopharmacol 66: 355-361.

Kim DH, Yoon BH, Kim YW, Lee S, Shin BY, Jung JW, Kim HJ, Lee YS, Choi JS, Kim SY, Lee KT, Ryu JH (2007) The seed extract of Cassia obtusifolia ameliorates learning and memory impairments induced by scopolamine or transient cerebral hypoperfusion in mice. J Pharmacol Sci 105: 82-93.

Kitanaka S, Nakayama T, Shibano T, Ohkoshi E, Takido M (1998) Antiallergic agent from natural sources. Structures and inhibitory effect of histamine release of naphthopyrone glycosides from seeds of Cassia obtusifolia L. Chem Pharm Bull (Tokyo) 46: 1650-1652.

Lee KJ, Choi JH, Khanal T, Hwang YP, Chung YC, Jeong HG (2008) Protective effect of caffeic acid phenethyl ester against carbon tetrachloride-induced hepatotoxicity in mice. Toxicology 248: 18-24.

Lei XG (2002) In vivo antioxidant role of glutathione peroxidase: evidence from knockout mice. Methods Ensymol 347: 213-225.

Manibusan MK, Odin M, Eastmond DA (2007) Postulated carbon tetrachloride mode of action: a review. J Environ Sci Health C Environ Carcinog Ecotoxicol Rev 25: 185-209.

Medina J, Moreno-Otero R (2005) Pathophysiological basis for antioxidant therapy in chronic liver disease. Drugs 65: 2445-2461.

Nwozo SO, Oyinloye BE (2011) Hepatoprotective effect of aqueous extract of Aframomum melegueta on ethanol-induced toxicity in rats. Acta Biochim Pol 58: 355-358.

Pahan K, Smith BT, Singh AK, Singh I (1997) Cytochrome P-450 2E1 in rat liver peroxisomes: downregulation by ischemia/reperfusioninduced oxidative stress. Free Radic Biol Med 23: 963-971.

Pradeep K, Mohan CV, Gobianand K, Karthikeyan S (2007) Effect of Cassia fistula Linn. leaf extract on diethylnitrosamine induced hepatic injury in rats. Chem Biol Interact 167: 12-18.

Roberts BJ, Shoaf SE, Song BJ (1995) Rapid changes in cytochrome P4502E1 (CYP2E1) activity and other P450 isozymes following ethanol withdrawal in rats. Biochem Pharmacol 49: 1665-1673.

Sheweita SA, Abd El-Gabar M, Bastawy M (2001a) Carbon tetrachloride-induced changes in the activity of phase II drug-metabolizing enzyme in the liver of male rats: role of antioxidants. Toxicology 165: $217-224$

Sheweita SA, El-Gabar MA, Bastawy M (2001b) Carbon tetrachloride changes the activity of cytochrome P450 system in the liver of male rats: role of antioxidants. Toxicology 169: 83-92.

Skinner CM, Rangasami J (2002) Preoperative use of herbal medicines: a patient survey. BrJ Anaesth 89: 792-795.

Song Z, Zhou Z, Chen T, Hill D, Kang J, Barve S, McClain C (2003) S-adenosylmethionine (SAMe) protects against acute alcohol induced hepatotoxicity in mice small star, filled. J Nutr Biochem 14: 591-597.

Srivastava A, Shivanandappa T (2006) Hepatoprotective effect of the aqueous extract of the roots of Decalepis hamiltonii against ethanolinduced oxidative stress in rats. Hepatol Res 35: 267-275.

Sung BK, Kim MK, Lee WH, Lee DH, Lee HS (2004) Growth responses of Cassia obtusifolia toward human intestinal bacteria. Fitoterapia 75: 505-509.

Tierney DJ, Haas AL, Koop DR (1992) Degradation of cytochrome P450 2E1: selective loss after labilization of the enzyme. Arch Biochem Biophys 293: 9-16.

Weerachayaphorn J, Chuncharunee A, Jariyawat S, Lewchalermwong B, Amonpatumrat S, Suksamrarn A, Piyachaturawat P (2010) Protection of centrilobular necrosis by Curcuma comosa Roxb. in carbon tetrachloride-induced mice liver injury. J Ethnopharmacol 129: 254-260. 
Wong FW, Chan WY, Lee SS (1998) Resistance to carbon tetrachloride-induced hepatotoxicity in mice which lack CYP2E1 expression. Toxicol Appl Pharmacol 153: 109-118.

Wu G, Fang YZ, Yang S, Lupton JR, Turner ND (2004) Glutathione metabolism and its implications for health. J Nutr 134: 489-492.

Yang CS, Chhabra SK, Hong JY, Smith TJ (2001) Mechanisms of inhibition of chemical toxicity and carcinogenesis by diallyl sulfide (DAS) and related compounds from garlic. I Nutr 131: 1041S1045 S.
Yue J, Peng R, Chen J, Liu Y, Dong G (2009) Effects of rifampin on CYP2E1-dependent hepatotoxicity of isoniazid in rats. Pharmacol Res 59: 112-119.

Yun-Choi HS, Kim JH, Takido M (1990) Potential inhibitors of platelet aggregation from plant sources, V. Anthraquinones from seeds of Cassia obtusifolia and related compounds. J Nat Prod 53: 630-633. Zeng T, Zhang CL, Song FY, Han XY, Xie KQ (2009) The modulatory effects of garlic oil on hepatic cytochrome P450s in mice. Hum Exp Toxicol 28: 777-783. 